\title{
Non-employment and low educational level as risk factors for inequitable treatment and mortality in heart failure: a population-based cohort study of register data
}

Anna Ohlsson ${ }^{1 *}$ (D) Nils Eckerdal ${ }^{2}$, Bertil Lindahl ${ }^{3}$, Marianne Hanning ${ }^{1}$ and Ragnar Westerling ${ }^{1 \wedge}$

\begin{abstract}
Background: The risk of heart failure is disproportionately high among the socioeconomically disadvantaged. Furthermore, socioeconomically deprived patients are at risk of inequitable access to heart failure treatment and poor outcomes. Non-employment as a risk factor in this respect has not previously been studied at the level of the individual. The aim of this register-based cohort study was to analyse equity in access to renin-angiotensin system blockers and mortality, by employment status and educational level.

Methods: The study population consisted of Swedish patients aged 20-64 years hospitalised for heart failure in July 2006-December 2010, without a heart failure hospitalisation within one year or more before index hospitalisation and without renin-angiotensin system blocker dispensation in the 6 months preceding index hospitalisation. Nonaccess to renin-angiotensin system blockers, measured as drug dispensations, was investigated by employment status and educational level through logistic regression. Cox regression models were used to obtain hazard ratios for all-cause death by educational level and employment status. Interaction analysis was used to test whether associations between access to treatment and mortality differed by employment status.

Results: Among the 3874 patients, 1239 (32\%) were women. The median age was 57 years. Fifty-three percent were employed. The non-employed patients had more comorbidity and lower access (68\%) to renin-angiotensin system blockers compared with the employed (82\%). The adjusted odds ratio for non-access to renin-angiotensin system blockers among the non-employed was 1.76. Non-employment was associated with an adjusted hazard ratio of 1.76 for death. Low educational level was associated with a higher death risk. Mortality was highest among the non-employed without access to renin-angiotensin system blockers and the association between access to renin-angiotensin system blockers and survival was slightly weaker in this group.

(Continued on next page)
\end{abstract}

\footnotetext{
* Correspondence: anna.ohlsson@pubcare.uu.se

Ragnar Westerling is deceased.

'Department of Public Health and Caring Sciences, Uppsala University, Box

564,75122 Uppsala, Sweden

Full list of author information is available at the end of the article
}

(c) The Author(s). 2021, corrected publication 2021. Open Access This article is licensed under a Creative Commons Attribution 4.0 International License, which permits use, sharing, adaptation, distribution and reproduction in any medium or format, as long as you give appropriate credit to the original author(s) and the source, provide a link to the Creative Commons licence, and indicate if changes were made. The images or other third party material in this article are included in the article's Creative Commons licence, unless indicated otherwise in a credit line to the material. If material is not included in the article's Creative Commons licence and your intended use is not permitted by statutory regulation or exceeds the permitted use, you will need to obtain permission directly from the copyright holder. To view a copy of this licence, visit http://creativecommons.org/ licenses/by/4.0/. The Creative Commons Public Domain Dedication waiver (http://creativecommons.org/publicdomain/zero/1. 0/) applies to the data made available in this article, unless otherwise stated in a credit line to the data. 
(Continued from previous page)

Conclusions: Non-employment and low educational level were associated with elevated mortality in heart failure. Non-employment was a risk factor for lower access to evidence-based treatment, and among the non-employed access to treatment was associated with a slightly smaller risk reduction than among the employed. The results underscore that clinicians need to be aware of the importance of socioeconomic factors in heart failure care.

Keywords: Heart failure, Renin-angiotensin system blockers, Equity in health care, Employment status, Educational level

\section{Background}

Heart failure (HF) is an increasing health problem globally [1]. HF incidence is disproportionately high among the socioeconomically disadvantaged and outcomes are poorer in this group [2-6]. Furthermore, there are indications of socioeconomic inequity in access to HF care, including evidence-based pharmacological HF treatment $[7,8]$.

One of the mortality-reducing evidence-based treatments in HF with reduced ejection fraction (HFrEF) is renin-angiotensin system blockers (RASb). Along with beta-blocker therapy, RASb have long been recommended in clinical guidelines as a first-line treatment for HFrEF. Thus, most HFrEF patients should receive such treatment. For HF with preserved ejection fraction (HFpEF), there is no evidence-based mortality-reducing medication.

Socioeconomic position has often been defined using occupation, and classified based on e.g., the degree of manual work and/or the amount of job control $[9,10]$. Occupational class is associated with health and mortality outcomes in a range of health problems [11], including HF [4]. Several other socioeconomic indicators, such as educational level and income, are also strongly associated with health outcomes [11]. However, according to Swedish data, avoidable mortality (preventable by health policy or health care measures) may differ more between those working and those not working than between different occupational classes [12]. Non-employment has been linked to low health care utilisation relative to perceived need [13]. In a previous study, we found that non-employed patients hospitalised for HF were at higher risk than those employed of not getting access to treatment with RASb [7].

Socioeconomic deprivation is associated with higher HF mortality [2, 3, 6]. Previous investigators have mainly studied education and income, or aggregated measures, and socioeconomic indicators have often been studied by area, rather than by individual $[2,3,6,14]$. Studies investigating individual employment status in relation to HF mortality are lacking. Furthermore, equity in access to RASb treatment by socioeconomic factors is incompletely studied, and results are conflicting $[5-7,14,15]$.

We aimed to study RASb access and mortality by educational level and employment status, in a population register cohort of hospitalised HF patients of working age, and to analyse possible excess mortality among nonemployed patients without access to RASb. We tested 1) whether a low educational level or non-employment was associated with non-exposure to RASb; 2) whether a low educational level or non-employment was associated with a higher risk of all-cause death; and 3) whether nonemployment was associated with additional mortality risk due to interaction with non-exposure to RASb.

\section{Methods \\ Data}

We used individual-level register data linked by unique personal identity numbers, from several Swedish total population registers: hospitalisation data from the $\mathrm{Na}$ tional Patient Register [16]; drug dispensations from the Prescribed Drug Register [17], cause of death from the Cause of Death Register [18]; and sociodemographic data from the Longitudinal Integration Database for Health Insurance and Labour Market Studies ("LISA" by its Swedish acronym) [19]. Coverage is $>99 \%$ for both inpatient care in the National Patient Register and drug dispensations in the Prescribed Drug Register. The Cause of Death Register contains all deaths among persons registered in the Swedish national registration at the time of their death. In LISA, coverage differs between variables. In this study, there were $1 \%$ missing data for educational level and $2.8 \%$ missing data for employment status. Missingness is reported by presenting the number actually analysed for each variable in the results section.

\section{Study population}

The study population comprised all patients aged 20-64 years who survived an index $\mathrm{HF}^{1}$ hospitalisation in the period 1st July 2006-31st December 2010, without a previous HF hospitalisation within one year or more before index hospitalisation and without RASb dispensation in the 6 months preceding index hospitalisation. The index hospitalisation was the first hospitalisation in the study period for each individual, and the index date was the discharge date for that hospitalisation. Figure 1

\footnotetext{
${ }^{1}$ International Classification of Diseases (ICD-10) codes: I11.0, I13.0, I13.2, I42.0, I42.3-I42.9, I50.0, I50.1, I50.9.
} 
depicts the selection of the study population, which consisted of 3874 individuals.

\section{Outcomes}

For analyses of the associations between low educational level or non-employment and non-exposure to RASb, the outcome was defined as at least one dispensation of any dose of either an angiotensin-converting enzyme inhibitor (ACEI) or an angiotensin receptor blocker $(\mathrm{ARB})^{2}$ during follow-up, for those surviving 30 days or more. For analyses of the associations of low educational level or non-employment with all-cause death, and the association of non-employment with additional mortality risk due to interaction with nonexposure to RASb, the outcome was death from any cause during follow-up.

\section{Exposures}

\section{Renin-angiotensin system blockers}

For survival analysis, exposure to RASb was defined as at least one dispensation of either an ACEI or an ARB at any time during follow-up. Using the date for the first dispensation after index hospitalisation, we calculated a time-dependent exposure variable for RASb, with time between index date and dispensation designated as unexposed, and time from dispensation until end of followup designated as exposed.

\section{Employment status}

Employment status was extracted from a LISA variable, gainful employment status, based on a) the presence of an income statement in November of the year in question, and b) a minimum yearly income (different levels by year, age and sex). We used the value for employment in the year before index hospitalisation. The original categorisation in LISA was:

- Gainfully employed: income statement from gainful employment in November the year in question \& income above the limit to be classified as continuously employed.

- Not continuously employed: income statement from gainful employment in November the year in question \& income below the limit to be classified as continuously employed.

- Not employed: no income statement from gainful employment in November the year in question.

We collapsed the two latter categories and dichotomised the variable into either employed or nonemployed.

\footnotetext{
${ }^{2}$ Anatomical Therapeutic Chemical class codes: C09A and C09B for ACEI; C09C and C09D for ARB.
}

\section{Education}

The highest attained educational level in the year before index for each individual was retrieved from LISA, where it was divided into 7 categories. We recategorised education as compulsory school ( $\leq 9$ years, upper secondary school (approximately 11-12 years), or post-secondary school (approximately $\geq 12$ years).

\section{Other covariates \\ Comorbidity}

Comorbidity was defined based on ICD-10 diagnoses (see Additional file 1, S Table 1) at any inpatient hospitalisation within 1.5 years before and including the index hospitalisation.

For the analysis of non-exposure to RASb, we adjusted for hypertension, angina pectoris, myocardial infarction, coronary artery bypass grafting (CABG), renal dysfunction, diabetes mellitus, psychiatric disease, and dementia.

For survival analyses, we adjusted for hypertension, angina pectoris, myocardial infarction, atrial fibrillation/ flutter, pacemaker, CABG, stroke, peripheral vascular disease, lung disease, renal dysfunction, diabetes mellitus, anaemia, dementia, cancer, liver disease, rheumatic disease, and psychiatric disease.

\section{Hospitalisation-free time}

The study entry time varied. The time free from hospitalisation before inclusion, i.e., between 1st July 2006 and index hospitalisation, was calculated for each individual and adjusted for.

\section{Other medication}

Beta-blockers or aldosterone antagonists, also guidelinerecommended treatments for HF, were taken into account as separate covariates. Individuals were defined as getting these therapies if they had at least one dispensation of either drug within one year after index hospitalisation.

\section{Statistical analysis}

Logistic regression was used to model the associations between low educational level and non-employment respectively, with non-exposure to RASb within 30 days, among those surviving at least 30 days. A multivariable model was furthermore adjusted for age, gender, comorbidity, other medication, and index year in addition to the covariates educational level and employment status. We also performed this analysis including all patients and defining RASb exposure as dispensation at any time during follow-up, as a sensitivity analysis.

Cox regression was used to model the associations between RASb exposure, low educational level, nonemployment, and all-cause death. The multivariable 


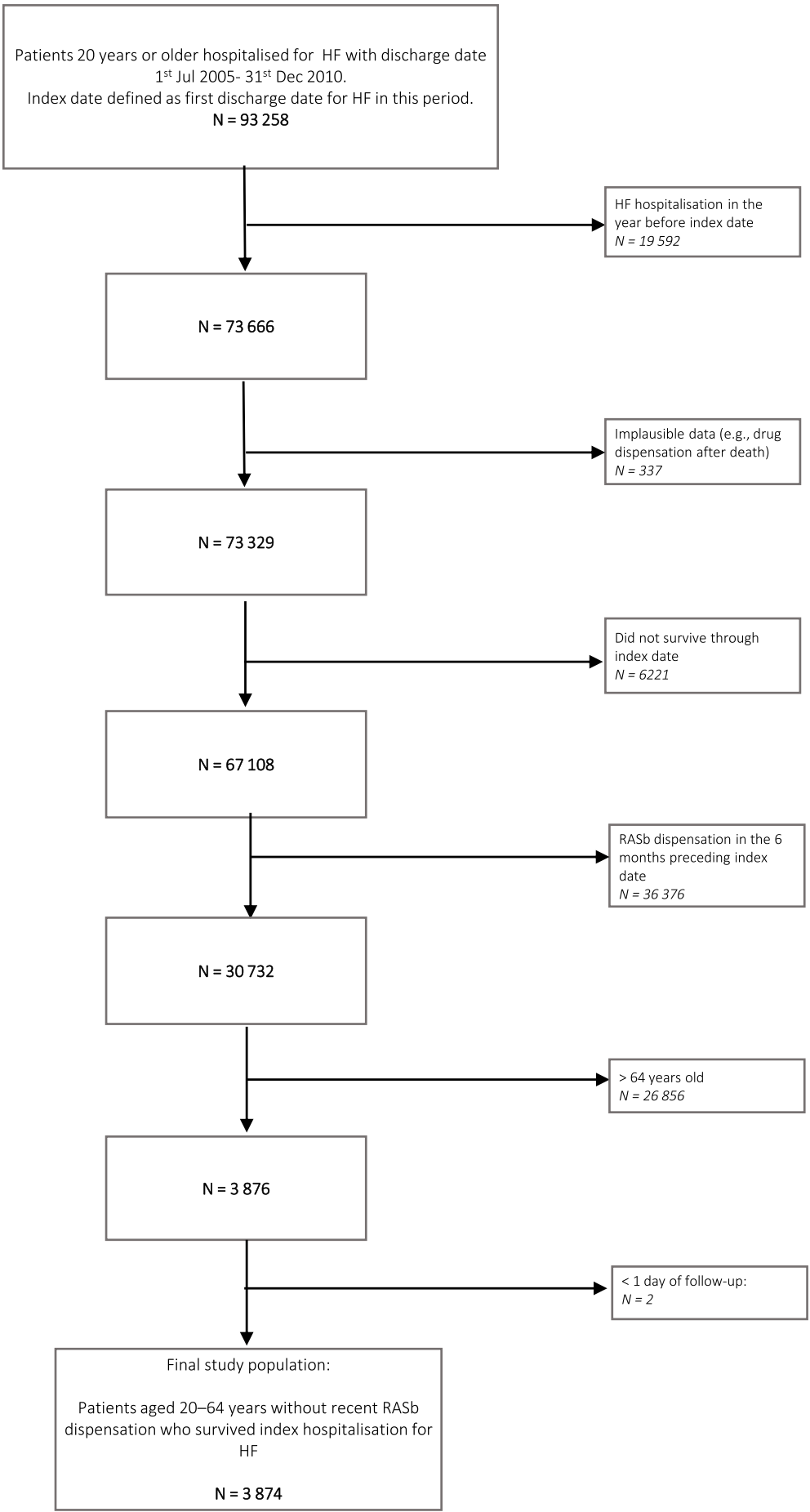

Fig. 1 Selection of study population

model was adjusted for age, gender, hospitalisation-free time, comorbidity, and other medication.

The assumption of proportional hazards was examined using univariate score tests and found to be satisfied in most cases, but not for the covariates RASb, betablocker or aldosterone antagonist in the fully adjusted model (model 5). Consequently, the Cox model would estimate an average hazard ratio (HR) across time from 
study inclusion for these variables. However, since the efficiency of RASb is well-studied, the time variations of the HR for RASb observed here were not investigated further.

We assessed multiplicative interaction between employment and RASb exposure by adding an interaction term to the Cox regression model, and by calculating the HR for each exposure category. Interaction was also assessed on the additive scale by calculating the relative excess risk due to interaction (RERI) [20].

\section{Additional analyses}

To examine the proportion of external causes among deaths, we tabulated external causes of death against employment status.

We examined the sensitivity of our results to underreporting of renal dysfunction by recoding a series of percentages of renal dysfunction non-cases into cases and running the Cox regression models under these conditions. This was repeated 10,000 times for each percentage. We also compared the hospitalisation-free time before study entry between the employed and nonemployed, using the chi-square test.

\section{Results}

\section{Characteristics}

As presented in Table 1, the overall median age was 57 years. The study cohort included 1239 (32\%) women. About half of the patients had upper secondary school as their highest educational level, and around 20\% had finished post-secondary school. Fifty-three percent were employed. Women were overrepresented among those with higher education and underrepresented among those with employment. The overall median yearly income was $€ 13,673$. $^{3}$ The median follow-up time for the entire cohort was 737 days. Hypertension (28\%) and atrial fibrillation/flutter (25\%) were the two most common comorbidities, followed by diabetes mellitus, lung disease, and myocardial infarction. Psychiatric disease was found in $9 \%$ of patients. Non-employed patients had higher rates of all comorbidities except cancer. Those with the lowest educational level had somewhat more comorbidities than those with the highest educational level. Among the 3731 patients surviving at least 30 days, RASb were dispensed to 2802 patients (75\%) during follow-up. Among the employed, $82 \%$ were dispensed $\mathrm{RASb}$, compared with $68 \%$ among the non-employed (Table 1). Patient characteristics by RASb dispensation within 30 days, among 30 -day survivors, are provided in $\mathrm{S}$ Table 2, in additional file 2 .

\footnotetext{
${ }^{3}$ Converted from Swedish krona; rate from the Swedish central bank (Riksbanken); https://www.riksbank.se/sv/statistik/ accessed 14 September 2020.
}

\section{Treatment}

Among those surviving 30 days or more, nonemployment was associated with a crude odds ratio (OR) of 2.22 (95\% confidence interval 1.90, 2.59) for not being dispensed RASb within 30 days of index date (Table 2). The adjusted OR was $1.76(1.47,2.11)$. Other covariates associated with non-exposure to RASb were female gender and lower age. Educational level was not associated with exposure to RASb. Estimates were very similar for the total cohort and when defining RASb exposure as dispensation at any time during follow-up.

\section{Mortality}

There were 501 (13\%) deaths from any cause among patients included in the multivariable Cox regression analyses. The one-year mortality was $7.6 \%$ overall and $11.2 \%$ among the non-employed (data not shown). Figure 2 depicts unadjusted cumulative hazards in the different patient groups, showing an excess mortality among the non-employed patients not dispensed RASb. As presented in Table 3, non-exposure to RASb was associated with a crude HR of $3.06(2.55,3.68)$ for death and nonemployment was associated with a crude HR of 2.86 $(2.36,3.45)$ for death. Lower vs higher educational level and higher vs lower age were also associated with higher crude HRs for death. Adjustments for age (model 2) and gender (model 3 ) scarcely changed the estimates. The estimates were attenuated in model 4 (including educational level, non-employment, hospitalisation-free time, comorbidity, and other medication), so that the overall HR for death associated with non-exposure to RASb was $1.66(1.33,2.06)$, and that associated with nonemployment was $1.76(1.43,2.17)$. Lower education remained significantly associated with a higher HR for death, and male gender became significantly associated with a higher HR for death in model 4.

In model 5, we added interaction terms to assess multiplicative interaction between non-exposure to RASb and non-employment. There was significant negative interaction between RASb exposure and employment status, reflecting a weaker association between $\mathrm{RASb}$ exposure and death in the non-employed. In model 5, the HR for death for those non-employed with RASb exposure was 2.21 (1.73, 2.84). For the employed without RASb exposure, the HR for death was 2.86 $(2.00,4.09)$ (Table 3). We also calculated the HR for death among those non-employed and without access to RASb (compared with those employed with access to RASb) and it was $2.96(2.19,4.00)$ (Table 4). The RERI for RASb and employment was calculated, to assess interaction on the additive scale, and found to be -1.16 $(-2.48,0.25)$, i.e., not significant.

The sensitivity analysis for renal dysfunction showed that underreporting would not substantially affect the 
Table 1 Patient characteristics by employment status and educational level

\begin{tabular}{|c|c|c|c|c|c|c|}
\hline \multirow[t]{3}{*}{ Total (\%) } & \multirow{4}{*}{$\begin{array}{l}\text { Total } \\
\text { cohort } \\
N=3874\end{array}$} & \multicolumn{5}{|c|}{ Distribution (\%) } \\
\hline & & Employed & Non-employed & $\begin{array}{l}\text { Post-secondary } \\
\text { school }\end{array}$ & $\begin{array}{l}\text { Upper secondary } \\
\text { school }\end{array}$ & $\begin{array}{l}\text { Compulsory } \\
\text { school }\end{array}$ \\
\hline & & \multicolumn{2}{|c|}{$N=3836$ (with data on employment) } & \multicolumn{3}{|c|}{$N=3767$ (with data on education) } \\
\hline & & $2046(53.3)$ & $1790(46.7)$ & $719(19.1)$ & $1818(48.3)$ & $1230(32.7)$ \\
\hline \multicolumn{7}{|l|}{ Age (years) } \\
\hline Median & 57 & 56 & 58 & 56 & 57 & 58 \\
\hline 25th percentile & 50 & 48 & 52 & 47 & 48 & 52 \\
\hline 75th percentile & 61 & 60 & 62 & 61 & 61 & 62 \\
\hline \multicolumn{7}{|l|}{ Gender } \\
\hline Women & $1239(32.0)$ & $585(28.6)$ & $648(36.2)$ & $263(36.6)$ & $583(32.1)$ & $366(29.8)$ \\
\hline Men & $2635(68.0)$ & $1461(71.4)$ & $1142(63.8)$ & $456(63.4)$ & $1235(67.9)$ & $864(70.2)$ \\
\hline \multicolumn{7}{|l|}{ Income $(€)^{a}$} \\
\hline Median & 13,673 & 17,490 & 11,240 & 17,279 & 13,808 & 12,356 \\
\hline 25th percentile & 10,308 & 12,769 & 8817 & 11,548 & 10,587 & 9760 \\
\hline 75th percentile & 19,962 & 23,466 & 14,000 & 24,365 & 19,548 & 18,346 \\
\hline \multicolumn{7}{|l|}{ Follow -up time (days) } \\
\hline Range & $1-1643$ & $1-1641$ & $1-1643$ & $1-1635$ & $1-1639$ & $1-1643$ \\
\hline Median & 737 & 777 & 688 & 738 & 726 & 746 \\
\hline 25th percentile & 322 & 372 & 281 & 307 & 333 & 312 \\
\hline 75th percentile & 1179 & 1207 & 1151 & 1135 & 1178 & 1192 \\
\hline \multicolumn{7}{|l|}{ Comorbidity } \\
\hline Hypertension & $1088(28.4)$ & $576(28.2)$ & $512(28.6)$ & $200(27.8)$ & $521(28.7)$ & 339 (27.6) \\
\hline Diabetes mellitus & $585(15.1)$ & $198(9.7)$ & $377(21.1)$ & $97(13.5)$ & $267(14.7)$ & $196(15.9)$ \\
\hline Angina pectoris & $213(5.5)$ & $93(4.5)$ & $117(6.5)$ & $34(4.7)$ & $103(5.7)$ & $68(5.5)$ \\
\hline Myocardial infarction & $424(10.9)$ & $193(9.4)$ & $225(12.6)$ & $62(8.6)$ & $206(11.3)$ & 143 (11.6) \\
\hline Atrial fibrillation/flutter & $958(24.7)$ & $517(25.3)$ & $429(24.0)$ & $176(24.5)$ & $434(23.9)$ & $323(26.3)$ \\
\hline Pacemaker & $115(3.0)$ & $56(2.7)$ & $58(3.2)$ & $28(3.9)$ & $49(2.7)$ & $34(2.8)$ \\
\hline Stroke & $120(3.1)$ & $36(1.8)$ & $84(4.7)$ & $17(2.4)$ & $59(3.2)$ & $42(3.4)$ \\
\hline Renal dysfunction & $208(5.4)$ & $69(3.4)$ & $137(7.7)$ & $29(4.0)$ & $107(5.9)$ & $67(5.4)$ \\
\hline Vascular disease & $65(1.7)$ & $25(1.2)$ & $40(2.2)$ & $8(1.1)$ & $31(1.7)$ & $25(2.0)$ \\
\hline Rheumatic disease & $65(1.7)$ & $20(1.0)$ & $45(2.5)$ & $10(1.4)$ & $28(1.5)$ & $27(2.2)$ \\
\hline Lung disease & $581(15.0)$ & $198(9.7)$ & $378(21.1)$ & $71(9.9)$ & $283(15.6)$ & $207(16.8)$ \\
\hline Liver disease & $92(2.4)$ & $33(1.6)$ & $59(3.3)$ & $13(1.8)$ & $45(2.5)$ & $32(2.6)$ \\
\hline CABG & $193(5.0)$ & $80(3.9)$ & $111(6.2)$ & $31(4.3)$ & $94(5.2)$ & $62(5.0)$ \\
\hline Anaemia & $176(4.5)$ & $44(2.2)$ & $131(7.3)$ & $23(3.2)$ & $91(5.0)$ & $58(4.7)$ \\
\hline Cancer & $118(3.0)$ & $64(3.1)$ & $53(3.0)$ & $22(3.1)$ & $50(2.8)$ & 44 (3.6) \\
\hline Dementia & $8(0.2)$ & $3(0.1)$ & $5(0.3)$ & $1(0.1)$ & $5(0.3)$ & $2(0.2)$ \\
\hline Psychiatric disease & $359(9.3)$ & $97(4.7)$ & $257(14.4)$ & $43(6.0)$ & $171(9.4)$ & $137(11.1)$ \\
\hline $\begin{array}{l}\text { RASb }<30 \text { days (among } \\
30 \text {-day survivors, } N=3731 \text { ) }\end{array}$ & $2802(75.1)$ & $1627(82.2)$ & $1157(67.5)$ & $524(75.0)$ & $1327(76.0)$ & $886(75.0)$ \\
\hline
\end{tabular}

RASb, Renin-angiotensin system blockers

CABG, coronary artery bypass grafting

a) Converted from Swedish krona; rate from the Swedish central bank (Riksbanken); https://www.riksbank.se/sv/statistik/ accessed 14 September 2020 
Table 2 Odds ratios (ORs) for non-dispensation of renin-angiotensin system blockers (RASb) within 30 days, among 30-day survivors.

\begin{tabular}{|c|c|c|c|c|}
\hline$N=3731$ & Crude OR & OR adjusted for age & $\begin{array}{l}\text { OR adjusted for } \\
\text { age and gender }\end{array}$ & $\begin{array}{l}\text { Multivariable model including: } \\
\text { employment, education, age }{ }^{a} \text {, } \\
\text { gender, comorbidity }{ }^{\mathrm{b}} \text {, other } \\
\text { medication }{ }^{c} \text {, and index year. }\end{array}$ \\
\hline \multicolumn{5}{|l|}{ Employment $(N=3694)$} \\
\hline Employed & Ref & Ref & Ref & Ref \\
\hline Non-employed & $2.22(1.90,2.59)$ & $2.28(1.95,2.66)$ & $2.20(1.88,2.57)$ & $1.76(1.47,2.11)$ \\
\hline \multicolumn{5}{|l|}{ Education $(N=3628)$} \\
\hline Compulsory school & $1.00(0.81,1.24)$ & $1.02(0.82,1.27)$ & $1.07(0.86,1.34)$ & $0.86(0.67,1.10)$ \\
\hline Upper secondary school & $0.95(0.77,1.16)$ & $0.95(0.78,1.17)$ & $0.99(0.80,1.21)$ & $0.84(0.67,1.06)$ \\
\hline Post-secondary school & Ref & Ref & Ref & Ref \\
\hline Age (years) & $0.99(0.98,1.00)$ & & & $0.99(0.98,1.00)$ \\
\hline Female gender & $1.99(1.70,2.32)$ & $1.98(1.69,2.30)$ & & $1.76(1.47,2.11)$ \\
\hline
\end{tabular}

${ }^{\mathrm{a} A g e}$ as continuous variable

${ }^{b}$ Comorbidity with: hypertension, angina pectoris, myocardial infarction, coronary artery bypass grafting, renal dysfunction, diabetes mellitus, dementia, psychiatric disease.

'Beta-blocker or aldosterone antagonist.

HRs for RASb non-exposure, employment, or their interaction. We did not find a higher proportion of external causes among the non-employed.

Hospitalisation-free time did not differ significantly between the employed and non-employed.

\section{Discussion}

The main findings of this study were lower access to RASb for the non-employed HF patients, higher mortality for the non-employed and those with low educational level, and a somewhat weaker association between RASb exposure and survival for the non-employed compared with the employed.

\section{Access to RASb}

The adjusted OR of 1.76 for the association between non-exposure to RASb and non-employment is noteworthy. To our knowledge, no other investigators have analysed access to RASb by employment status. In a Dutch primary care population where individual-level socioeconomic status was self-reported and defined mainly by occupation, triple treatment (i.e., diuretics, $\mathrm{RASb}$, and beta-blocker) and beta-blocker treatment were

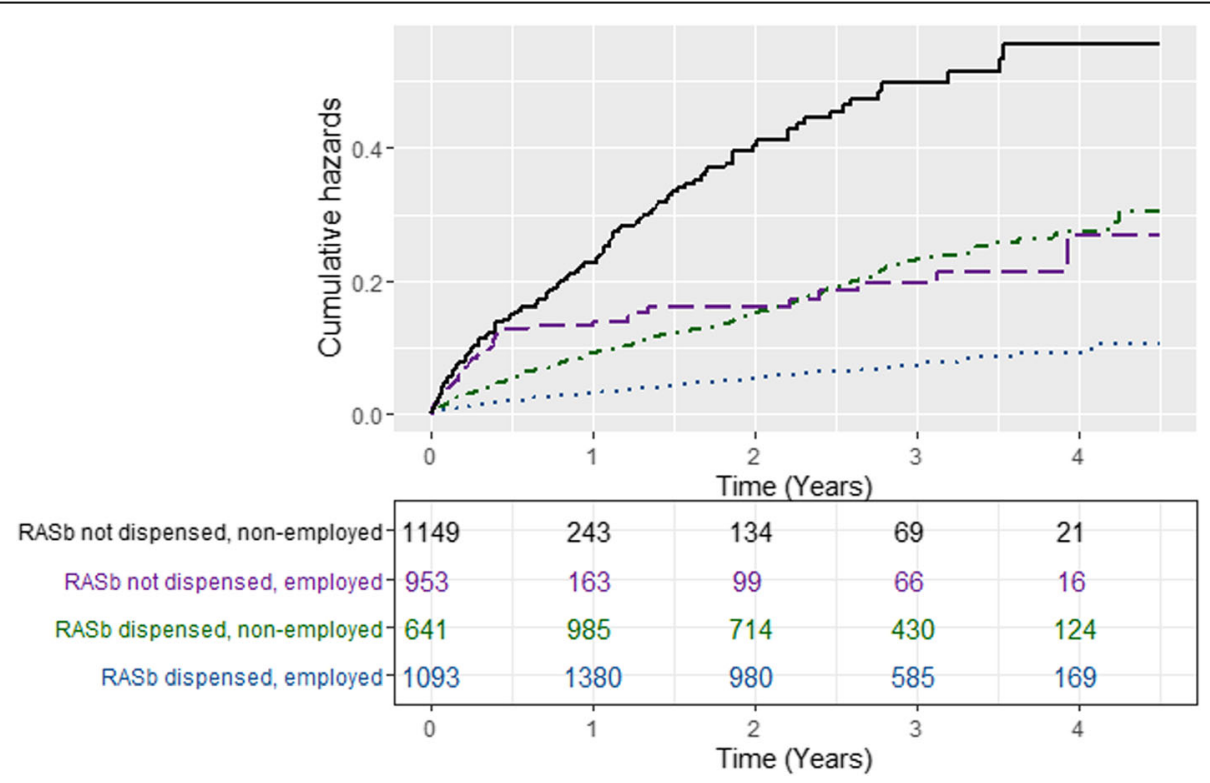

Fig. 2 Unadjusted cumulative hazard curves for death from all causes, by exposure group. Legend: Cumulative hazard curves for the four groups included in the accompanying table. The table shows group sizes over time. A steep slope indicates a period of high mortality rate 
Table 3 Hazard ratios (HRs) for all-cause death

\begin{tabular}{|c|c|c|c|c|c|}
\hline$N=3874$ & Crude HR & $\begin{array}{l}\text { Model } 2 \\
\text { HR adjusted } \\
\text { for age }\end{array}$ & $\begin{array}{l}\text { Model } 3 \\
\text { HR adjusted } \\
\text { for age and } \\
\text { gender }\end{array}$ & $\begin{array}{l}\text { Model } 4 \\
\text { Multivariable model } \\
\text { including: employment, } \\
\text { education, hospitalisation-free } \\
\text { time, comorbidity }{ }^{\mathrm{a}} \text {, other } \\
\text { medication }^{\mathrm{b}} \text {. }\end{array}$ & $\begin{array}{l}\text { Model } 5 \\
\text { Multivariate model } \\
\text { including: employment, } \\
\text { education, hospitalisation- } \\
\text { free time, comorbidity } \\
\text { other medication }{ }^{\mathrm{b}} \text {, and inter } \\
\text { action: no RASb*non- } \\
\text { employment }\end{array}$ \\
\hline No RASb dispensed & $\begin{array}{l}3.06 \\
(2.55,3.68)\end{array}$ & $\begin{array}{l}3.23 \\
(2.68,3.89)\end{array}$ & $\begin{array}{l}3.25 \\
(2.69,3.92)\end{array}$ & $\begin{array}{l}1.66 \\
(1.33,2.06)\end{array}$ & $\begin{array}{l}2.86 \\
(2.00,4.09)\end{array}$ \\
\hline \multicolumn{6}{|l|}{ Employment $(N=3836)$} \\
\hline Employed & Ref & Ref & Ref & Ref & Ref \\
\hline Non-employed & $\begin{array}{l}2.86 \\
(2.36,3.45)\end{array}$ & $\begin{array}{l}2.70 \\
(2.23,3.27)\end{array}$ & $\begin{array}{l}2.69 \\
(2.22,3.26)\end{array}$ & $\begin{array}{l}1.76 \\
(1.43,2.17)\end{array}$ & $\begin{array}{l}2.21 \\
(1.73,2.84)\end{array}$ \\
\hline \multicolumn{6}{|l|}{ Education $(N=3767)$} \\
\hline Compulsory school & $\begin{array}{l}1.81 \\
(1.36,2.42)\end{array}$ & $\begin{array}{l}1.67 \\
(1.25,2.23)\end{array}$ & $\begin{array}{l}1.67 \\
(1.25,2.23)\end{array}$ & $\begin{array}{l}1.37 \\
(1.02,1.84)\end{array}$ & $\begin{array}{l}1.39 \\
(1.03,1.86)\end{array}$ \\
\hline Upper secondary school & $\begin{array}{l}1.61 \\
(1.21,2.13)\end{array}$ & $\begin{array}{l}1.61 \\
(1.22,2.13)\end{array}$ & $\begin{array}{l}1.61 \\
(1.22,2.13)\end{array}$ & $\begin{array}{l}1.38 \\
(1.04,1.84)\end{array}$ & $\begin{array}{l}1.40 \\
(1.06,1.86)\end{array}$ \\
\hline Post-secondary school & Ref & Ref & Ref & Ref & Ref \\
\hline Age & $\begin{array}{l}1.05 \\
(1.04,1.06)\end{array}$ & & & $\begin{array}{l}1.03 \\
(1.02,1.05)\end{array}$ & $\begin{array}{l}1.03 \\
(1.02,1.05)\end{array}$ \\
\hline Male gender & $\begin{array}{l}0.86 \\
(0.72,1.03)\end{array}$ & $\begin{array}{l}0.87 \\
(0.72,1.04)\end{array}$ & & $\begin{array}{l}1.24 \\
(1.02,1.51)\end{array}$ & $\begin{array}{l}1.23 \\
(1.01,1.50)\end{array}$ \\
\hline $\begin{array}{l}\text { Interaction: No RASb*non- } \\
\text { employment }(N=3836)\end{array}$ & & & & & $\begin{array}{l}0.47 \\
(0.31,0.70)\end{array}$ \\
\hline
\end{tabular}

RASb, Renin-angiotensin system blockers

a) Comorbidity with: hypertension, angina pectoris, myocardial infarction, atrial fibrillation/flutter, pacemaker, coronary artery bypass grafting (CABG), stroke, peripheral vascular disease, lung disease, renal dysfunction, diabetes mellitus, anaemia, dementia, cancer, liver disease, rheumatic disease, psychiatric disease b) Beta-blocker or aldosterone antagonist

to a greater extent prescribed to those with higher socioeconomic status. Several other studies found no differences in RASb access by socioeconomic factors $[6,14,15]$.

We defined access to treatment as being dispensed RASb at a pharmacy. Thus, lower access for the nonemployed could have two main causes; 1 ) less treatment was prescribed to this group, or 2) the non-employed were less likely to collect treatments prescribed.

Table 4 Adjusted hazard ratios for categories of RASb exposure and employment, with the reference employment \& RASb (confidence intervals in parentheses).

\begin{tabular}{|c|c|c|c|}
\hline & & RASb & \\
\hline & & No & Yes \\
\hline \multirow[t]{4}{*}{ Employment } & No & 2.96 & 2.21 \\
\hline & & $(2.19,4.00)$ & $(1.73,2.84)$ \\
\hline & Yes & 2.86 & 1 \\
\hline & & $(2.00,4.09)$ & (Ref) \\
\hline
\end{tabular}

RASb, Renin-angiotensin system blockers

Adjustments for: age; gender; hospitalisation-free time; comorbidity with: hypertension, angina pectoris, myocardial infarction, atrial fibrillation/flutter, pacemaker, coronary artery bypass grafting (CABG), stroke, peripheral vascular disease, lung disease, renal dysfunction, diabetes mellitus, anaemia, dementia, cancer, liver disease, rheumatic disease, psychiatric disease; beta-blocker or aldosterone antagonist therapy
Non-prescription could be medically motivated in case of medication intolerance or contraindications for RASb (e.g., worsening renal dysfunction during RASb treatment); due to HFpEF, where RASb are neither effective nor recommended; or due to prescribers' bias against non-employed patients, leading to substandard treatment.

In the present study, we adjusted for comorbidity that affected the chance of receiving a RASb prescription (e.g., renal dysfunction and hypertension). Although data on type of HF were lacking, there is no plausible reason that HFpEF would be more common in the nonemployed and justify less RASb prescription. Previous studies have shown that care providers' bias against disadvantaged patients may contribute to health disparities [21]. Such bias could explain some of our findings.

Possible reasons for non-employed patients to refrain from collecting prescribed drugs include financial constraints, psychiatric morbidity, and low health literacy. A low health literacy, i.e., limited "knowledge, motivation and competencies of accessing, understanding, appraising and applying information to form judgment and make decisions concerning healthcare, disease prevention and health promotion" [22], has been shown to influence medication adherence in $\operatorname{HF}[23,24]$. Health 
literacy is associated with socioeconomic factors, mainly educational attainment, and with worse health, such as poorer blood pressure control [25].

Furthermore, depression or other psychiatric morbidity, including substance abuse, might coexist with nonemployment, and contribute to lower motivation and less resources to maintain health. We attempted to account for this by adjusting for psychiatric diagnoses.

Although we do not know the exact reasons, the nonemployed hadlower access to RASb, which possibly reflects inequitable treatment of this patient group.

\section{Mortality}

The overall risk for all-cause death was considerably higher (HR 1.76) for the non-employed HF patients than for those employed, and higher for those with up to secondary vs post-secondary education, even after adjustments.

In the general population, unemployment is associated with higher all-cause and cause-specific mortality [26-29]. Although such associations may be the result of so-called health selection into employment [30], there is support for at least a partial causal effect of unemployment on mortality $[27,31,32]$. Possible mechanisms linking unemployment to health outcomes include financial strain, psychological health effects, social norms and stigmatisation, and unhealthy behaviours [33-35]. The relationships between mortality and other socioeconomic indicators, e.g., education and income, are also well-established [11, $36]$. In our sample, the employment rate (53\%) was relatively low, compared with the general Swedish population (age 15-74 years) where employment in 2005-2010 was around $65 \%$ overall: $63 \%$ among women and $67 \%$ among men [37]. In our data, $33 \%$ had only compulsory education, compared with $20 \%$ in the general population, and $20 \%$ had post-secondary education, compared with around $35 \%$ in the general population. The median income in our data (over the entire study period) was only around $63 \%$ of the Swedish median for 2005. Interestingly, in our cohort, women were under-represented among the employed, but over-represented among those with postsecondary education. These relationships mirror those in the general population [37], and are noteworthy considering that the median income for those employed in our sample was slightly higher than that for those with postsecondary education.

In HF, other investigators have also found higher mortality for some socioeconomic measures, such as income $[38,39]$, or composite measures $[2,3,40]$. Such increases in mortality have been associated with comorbid conditions or unhealthy behaviours. For example, Witte et al. found that non-cardiovascular hospitalisation, not HF symptoms or access to therapy, explained the higher mortality associated with socioeconomic deprivation in a UK cohort of outpatients treated in cardiology clinics
[2]. However, another UK study by Lawson and colleagues concluded that comorbidities and lifestyle factors did not fully explain the higher mortality in the socioeconomically deprived group, and that the focus should be on health care and social interventions to improve equity [3]. In a Catalonian HF population, lower income was independently associated with higher mortality and lower access to specialised care, and the researchers highlighted the need for tailored health care management for patients with low socioeconomic status [38].

Cardiovascular morbidity and mortality are associated with a number of lifestyle factors, such as smoking, alcohol consumption, and diet, and with obesity. Data on these factors were not available in this study, but it is possible that they contributed to higher mortality among the non-employed. Nearly all of the measured comorbidities in this study were more common among the nonemployed, particularly diabetes mellitus, lung disease, and psychiatric disease. Notably, diabetes mellitus type 2 is closely associated with obesity, and lung disease is more prevalent in smokers. Although the differences in comorbidity are relevant and consistent with previous research on other socioeconomic factors, they did not account for all of the differences in HRs for death in our data.

Thus, in contrast to the conclusions by Witte et al. [2], our results prompt the question of whether lower access to treatment is in fact part of the reason for the higher mortality among the non-employed in this hospitalised Swedish cohort, and whether the Swedish health care system is delivering equitable HF care.

\section{Interaction analysis}

The non-employed patients in our cohort were dispensed less RASb and had the highest mortality of the studied groups.

The unadjusted cumulative hazard was highest in the non-exposed and non-employed group and lowest in the exposed and employed (Fig. 1).

The weaker association between RASb access and survival among the non-employed in our study, although small in magnitude, was statistically significant and possibly clinically relevant. There is no expected biological difference due to non-employment per se, that would explain a lower effectiveness. Thus, such a difference in the association of RASb with survival would more likely be related to lifestyle factors or comorbidity associated with non-employment.

The likelihood of actual intake of dispensed drugs may differ between groups, as may the propensity to repeatedly collect drugs following a first dispensation. Again, health literacy or psychiatric morbidity may affect both these aspects of drug adherence. Health literacy has been found to mediate the relationship between subjective social status and depressive symptoms among HF patients 
[41]. According to an overview of systematic reviews, medication adherence in chronic diseases was negatively impacted by depression, and might be greater in those with higher socioeconomic status and employment [42].

Alternatively, the weaker association between RASb and survival could be due to causes of death neither affected by RASb nor related to measured comorbidity. Noncardiovascular hospitalisation and mortality explained the higher mortality associated with low socioeconomic status in a HF cohort in UK [2]. Furthermore, in a study by our research group, unemployment was associated with higher mortality from external causes, particularly suicides [43]. We did not find any such association between employment and external causes of death in the present data, although this could be due to a very small number of external deaths: only $2.5 \%$ of all deaths.

\section{Strengths and limitations}

To our knowledge, this study is the first in which total population individual-level data on employment status and educational level were used to analyse these socioeconomic factors in relation to access to treatment and mortality. The Swedish health care and demographic population registers used are of high quality.

However, because of the observational study design, we could not confirm causality or refute residual confounding.

A specific limitation of this study, due to the nature of the register data, was that EF and hence HFpEF/HFrEF status could not be accounted for. As there is no clear evidence for RASb treatment in HFpEF, guidelines do not recommend this treatment, and thus true eligibility for RASb for the patients in our cohort was not fully elucidated. This is a limitation for the interpretation of inequity in RASb access.

Disease severity was not measured, and may have confounded the association between employment and death, i.e., the non-employed patients could be non-employed for reasons related to a more severe form of HF. Sick leave/disability pension were not distinguishable from other types of non-employment in our data, and persons on sick leave due to severe HF would be classified as non-employed. Moreover, individuals might fail to obtain or retain a job due to poor health or disease severity-related factors. Thus, health selection was another potential methodological issue. However, the way patients were selected should mitigate the lack of disease severity data. Firstly, all patients were hospitalised for $\mathrm{HF}$, indicating a similar disease severity, and they had a HF hospitalisation-free interval of at least one year before the index date. All included patients were also without RASb for 6 months prior to the index hospitalisation. Furthermore, those employed and those unemployed had similar hospitalisation-free time before index, indicating similar health care needs and comparable disease severity. We adjusted analyses for hospitalisation-free time. Therefore, although we lack data on HFpEF/HFrEF and disease severity, we believe that non-employed and employed patients should be fairly comparable in this regard, and confounding due to more severe HF consequently limited. Lastly, nonemployment was registered in the year before the index date, thus preceding the index hospitalisation, which may mitigate the risk of health selection.

Comorbidity data was available only for the 1.5 years prior to the index date and based only on the ICD-10 codes of hospitalisations registered in the National Patient Register. Thus, comorbidity was likely underreported. We do not know if such underreporting was differential with respect to employment status or educational level. However, non-employed persons have been found to be more likely than the employed to abstain from seeking health care despite a need [13], which might increase the risk of underreporting.

Renal dysfunction is important as a possible confounder, as it is associated with higher mortality in HF [44] and may decrease the chance of receiving RASb. While renal dysfunction has been more prevalent in most other HF populations, our cohort was younger than most, and we excluded those with a recent RASb dispensation, which should lower the true proportion of renal dysfunction in the remaining cohort. Furthermore, our sensitivity analysis did not indicate any significant bias in our data due to underreporting of renal dysfunction.

\section{Clinical implications}

Potential clinical implications of this study are that caregivers should consider socioeconomic disadvantage such as non-employment as a risk factor among HF patients, and adapt treatment accordingly. Closer follow-up may be appropriate. Health literacy could be an important factor, as well as psychiatric morbidity. Addressing health-related lifestyle risk factors might be especially important in this group. Health care has the potential to mitigate socioeconomic inequity in health. To inform such improvements in equity, research on the mechanisms behind these findings is needed. This would require data with more detailed clinical variables such as $\mathrm{EF}$, and prescription data to assess drug adherence by socioeconomic factors.

\section{Conclusions}

We have demonstrated that non-employment and low educational level were risk factors for elevated mortality among HF patients. Non-employment was associated with lower access to evidence-based treatment with RASb, which may constitute inequitable treatment; and 
access to RASb treatment was associated with a somewhat smaller risk reduction among the non-employed than among the employed. Non-employed HF patients thus appeared to have a higher death risk whether or not they received treatment.

\section{Abbreviations}

ACEl: Angiotensin-converting enzyme inhibitor; ARB: Angiotensin receptor blocker; HF: Heart failure; HFpEF: Heart failure with preserved ejection fraction; HFrEF: Heart failure with reduced ejection fraction; HR: Hazard ratio; ICD-10: International Classification of Diseases, tenth revision; LISA: Swedish acronym for the Longitudinal Integration Database for Health Insurance and Labour Market Studies; OR: Odds ratio; RAS: Renin angiotensin system; RASb: Renin angiotensin system blockers; RERI: Relative excess risk due to interaction

\section{Supplementary Information}

The online version contains supplementary material available at https://doi. org/10.1186/s12889-021-10919-1.

Additional file 1 Table S1. International Classification of Diseases (ICD10) codes used to define comorbidity.

Additional file 2 Table S2. Patient characteristics among 30-day survivors by renin-angiotensin system blocker (RASb) dispensation within 30 days.

\section{Acknowledgements}

The authors wish to acknowledge Ulrika Winblad for efficiently facilitating and supporting this work.

\begin{abstract}
Authors' contributions
RW was a major contributor in the conception and design of the study, the acquisition of data, the execution of the study, and had an active role in discussing and interpreting the results, as well as critically revising the manuscript before he sadly passed away. AO, a PhD student and the corresponding author, contributed to the planning and design of the study, acquisition of data, was responsible for the datasets, performed much of the data management and some of the analyses, and was responsible for drafting and revising the paper. $\mathrm{NE}$, a statistician and PhD student, performed some data management, and contributed with planning, execution and interpretation of analyses, production of figures, and critical revision of the manuscript. BL contributed to the design of the study and was a major contributor in critically revising the manuscript. MH was involved in planning the study and in critically revising the manuscript. All authors read and approved the final manuscript.
\end{abstract}

\section{Funding}

This study was partially funded by The Swedish Research Council for Health, Working Life and Welfare (Swedish: FORTE-Forskningsrådet om Hälsa, Arbetsliv och Välfärd) (grant number 2015-00480). The funding body had no part in the design of the study, the collection, analysis, or interpretation of data, nor in writing the manuscript. Open access funding provided by Uppsala University.

\section{Availability of data and materials}

The datasets generated and analysed during the current study are not publicly available due to the nature of the data, being sensitive personal information. The data, or parts thereof, may be available from the corresponding author on reasonable request from authorised persons. The registers from which the study data were obtained are not open to public access. The registers are held at The National Board of Health and Welfare (https://www.socialstyrelsen.se/en/statistics-and-data/registers/registerinformation/), and at Statistics Sweden (https://www.scb.se/en/services/ ordering-data-and-statistics/guidance-for-researchers-and-universities/vilkamikrodata-finns/longitudinella-register/longitudinal-integrated-database-forhealth-insurance-and-labour-market-studies-lisa/).

\section{Declarations}

\section{Ethics approval and consent to participate}

The present study was originally approved by the Swedish Central Ethical Review Board (reg. no. Ö 29-2011), including permission to access and use the present data from Swedish population registers held at public agencies.. Due to the death of the original applicant, Ragnar Westerling, who was the senior researcher accountable for the research project, an amendment was submitted and approved by the Swedish Ethical Review Authority; registration number 2020-04203. The study conforms to the Declaration of Helsinki. Due to the nature of the study, consent to participate was not possible to obtain.

\section{Consent for publication}

Not applicable.

\section{Competing interests}

The authors declare that they have no competing interests.

\section{Author details}

'Department of Public Health and Caring Sciences, Uppsala University, Box 564, 75122 Uppsala, Sweden. ${ }^{2}$ Department of Statistics, Uppsala University, Box 513, 75120 Uppsala, Sweden. ${ }^{3}$ Department of Medical Sciences, Uppsala University, 75185 Uppsala, Sweden.

Received: 18 November 2020 Accepted: 26 April 2021

Published online: 02 June 2021

\section{References}

1. Ziaeian B, Fonarow GC. Epidemiology and aetiology of heart failure. Nat Rev Cardiol. 2016;13(6):368-78. https://doi.org/10.1038/nrcardio.2016.25.

2. Witte KK, Patel PA, Walker AMN, Schechter CB, Drozd M, Sengupta A, et al. Socioeconomic deprivation and mode-specific outcomes in patients with chronic heart failure. Heart. 2018;104(12):993-8. https://doi.org/10.1136/hea rtjnl-2017-312539.

3. Lawson CA, Zaccardi F, Squire I, Ling S, Davies MJ, Lam CSP, et al. 20-year trends in cause-specific heart failure outcomes by sex, socioeconomic status, and place of diagnosis: a population-based study. Lancet Public Health. 2019;4(8):e406-e20. https://doi.org/10.1016/S2468-2667(19)30108-2.

4. Schaufelberger M, Rosengren A. Heart failure in different occupational classes in Sweden. Eur Heart J. 2007;28(2):212-8. https://doi.org/10.1093/ eurheartj/ehl435.

5. McAlister FA, Murphy NF, Simpson CR, Stewart S, MacIntyre K, Kirkpatrick M, et al. Influence of socioeconomic deprivation on the primary care burden and treatment of patients with a diagnosis of heart failure in general practice in Scotland: population based study. Bmj. 2004;328(7448):1110. https://doi.org/10.1136/bmj.38043.414074.EE.

6. Rathore SS, Masoudi FA, Wang Y, Curtis JP, Foody JM, Havranek EP, et al. Socioeconomic status, treatment, and outcomes among elderly patients hospitalized with heart failure: findings from the National Heart Failure Project. Am Heart J. 2006;152(2):371-8. https://doi.org/10.1016/j.ahj.2005.12.002.

7. Ohlsson $A$, Lindahl $B$, Hanning M, Westerling R. Inequity of access to ACE inhibitors in Swedish heart failure patients: a register-based study. J Epidemiol Community Health. 2016;70(1):97-103. https://doi.org/10.1136/ jech-2015-205738.

8. Lund LH, Carrero JJ, Farahmand B, Henriksson KM, Jonsson A, Jernberg T, et al. Association between enrolment in a heart failure quality registry and subsequent mortality-a nationwide cohort study. Eur J Heart Fail. 2017;19(9): 1107-16. https://doi.org/10.1002/ejhf.762.

9. Galobardes B, Shaw M, Lawlor DA, Lynch JW, Davey SG. Indicators of socioeconomic position (part 2). J Epidemiol Community Health. 2006;60(2): 95-101. https://doi.org/10.1136/jech.2004.028092.

10. Galobardes B, Shaw M, Lawlor DA, Lynch JW, Davey SG. Indicators of socioeconomic position (part 1). J Epidemiol Community Health. 2006;60(1): 7-12. https://doi.org/10.1136/jech.2004.023531.

11. Mackenbach JP, Stirbu I, Roskam AJ, Schaap MM, Menvielle G, Leinsalu M, et al. Socioeconomic inequalities in health in 22 European countries. N Engl J Med. 2008;358(23):2468-81. https://doi.org/10.1056/NEJMsa0707519.

12. Westerling R, Gullberg A, Rosén M. Socioeconomic differences in 'avoidable' mortality in Sweden 1986-1990. Int J Epidemiol. 1996;25(3):560-7. https:// doi.org/10.1093/ije/25.3.560. 
13. Ahs AM, Westerling R. Health care utilization among persons who are unemployed or outside the labour force. Health Policy. 2006;78(2-3):178-93. https://doi.org/10.1016/j.healthpol.2005.10.010.

14. Bongers FJ, Schellevis FG, Bakx C, van den Bosch WJ, van der Zee J. Treatment of heart failure in Dutch general practice. BMC Fam Pract. 2006; 7(1):40. https://doi.org/10.1186/1471-2296-7-40.

15. Conrad N, Judge A, Canoy D, Tran J, O'Donnell J, Nazarzadeh M, et al. Diagnostic tests, drug prescriptions, and follow-up patterns after incident heart failure: a cohort study of 93,000 UK patients. PLoS Med. 2019;16(5): e1002805. https://doi.org/10.1371/journal.pmed.1002805.

16. Swedish National Board of Health and Welfare. Swedish National Patient Register [Web page] https://www.socialstyrelsen.se/en/statistics-and-data/ registers/register-information/the-national-patient-register/. Accessed 12 May 2021

17. Swedish National Board of Health and Welfare. Swedish Prescribed Drug Register [Web page] https://www.socialstyrelsen.se/en/statistics-and-data/ registers/register-information/the-swedish-prescribed-drug-register/. Accessed 12 May 2021

18. Swedish National Board of Health and Welfare. Swedish Cause of Death Register [Web page] https://www.socialstyrelsen.se/statistik-och-data/ register/alla-register/dodsorsaksregistret/ [Swedish]. Accessed 12 May 2021.

19. Statistics Sweden (SCB). Longitudinal integrated database for health insurance and labour market studies (LISA) [Web page] https://www.scb.se/en/services/ ordering-data-and-statistics/guidance-for-researchers-and-universities/vilkamikrodata-finns/longitudinella-register/longitudinal-integrated-database-forhealth-insurance-and-labour-market-studies-lisa/. Accessed 12 May 2021.

20. Li R, Chambless L. Test for additive interaction in proportional hazards models. Ann Epidemiol. 2007;17(3):227-36. https://doi.org/10.1016/j.a nnepidem.2006.10.009

21. Haider AH, Schneider EB, Sriram N, Dossick DS, Scott VK, Swoboda SM, et al. Unconscious race and social class bias among acute care surgical clinicians and clinical treatment decisions. JAMA Surg. 2015;150(5):457-64. https://doi. org/10.1001/jamasurg.2014.4038.

22. Sorensen K, Van den Broucke S, Fullam J, Doyle G, Pelikan J, Slonska Z, et al. Health literacy and public health: a systematic review and integration of definitions and models. BMC Public Health. 2012;12(1):80. https://doi.org/1 0.1186/1471-2458-12-80

23. Mixon AS, Myers AP, Leak CL, Lou Jacobsen JM, Cawthon C, Goggins KM, et al. Characteristics associated with postdischarge medication errors. Mayo Clin Proc. 2014;89(8):1042-51. https://doi.org/10.1016/j.mayocp.2014.04.023.

24. Noureldin M, Plake KS, Morrow DG, Tu W, Wu J, Murray MD. Effect of health literacy on drug adherence in patients with heart failure. Pharmacotherapy. 2012;32(9):819-26. https://doi.org/10.1002/j.1875-9114.2012.01109.x.

25. Pandit AU, Tang JW, Bailey SC, Davis TC, Bocchini MV, Persell SD, et al. Education, literacy, and health: mediating effects on hypertension knowledge and control. Patient Educ Couns. 2009;75(3):381-5. https://doi. org/10.1016/j.pec.2009.04.006.

26. Dunlavy AC, Garcy AM, Rostila M. Educational mismatch and health status among foreign-born workers in Sweden. Soc Sci Med. 2016;154:36-44. https://doi.org/10.1016/j.socscimed.2016.02.018.

27. Garcy AM, Vagero D. The length of unemployment predicts mortality, differently in men and women, and by cause of death: a six year mortality follow-up of the Swedish 1992-1996 recession. Soc Sci Med. 2012:74(12): 1911-20. https://doi.org/10.1016/j.socscimed.2012.01.034.

28. Nie J, Wang J, Aune D, Huang W, Xiao D, Wang Y, et al. Association between employment status and risk of all-cause and cause-specific mortality: a population-based prospective cohort study. J Epidemiol Community Health. 2020;74(5):428-36. https://doi.org/10.1136/jech-2019-213179.

29. Kriegbaum M, Lund R, Schmidt L, Rod NH, Christensen U. The joint effect of unemployment and cynical hostility on all-cause mortality: results from a prospective cohort study. BMC Public Health. 2019;19(1):293. https://doi. org/10.1186/s12889-019-6622-7

30. Lundin A, Lundberg I, Hallsten L, Ottosson J, Hemmingsson T. Unemployment and mortality--a longitudinal prospective study on selection and causation in 49321 Swedish middle-aged men. J Epidemiol Community Health. 2010;64(1):22-8. https://doi.org/10.1136/jech.2008.079269.

31. Vagero D, Garcy AM. Does unemployment cause long-term mortality? Selection and causation after the 1992-96 deep Swedish recession. Eur J Pub Health. 2016;26(5):778-83. https://doi.org/10.1093/eurpub/ckw053.

32. Helgesson M, Johansson B, Nordqvist T, Lundberg I, Vingard E. Unemployment at a young age and later sickness absence, disability pension and death in native swedes and immigrants. Eur J Pub Health. 2013;23(4):606-10. https://doi.org/10.1093/eurpub/cks099.

33. Bartley M. Unemployment and ill health: understanding the relationship. J Epidemiol Community Health. 1994;48(4):333-7. https:/doi.org/10.1136/jech.48.4.333.

34. Backhans MC, Hemmingsson T. Unemployment and mental health--who is (not) affected? Eur J Pub Health. 2012;22(3):429-33. https://doi.org/10.1093/ eurpub/ckr059.

35. De Moortel D, Hagedoorn P, Vanroelen C, Gadeyne S. Employment status and mortality in the context of high and low regional unemployment levels in Belgium (2001-2011): a test of the social norm hypothesis across educational levels. PLoS One. 2018;13(2):e0192526. https://doi.org/10.1371/ journal.pone.0192526.

36. Mackenbach JP, Kulhanova I, Menvielle G, Bopp M, Borrell C, Costa G, et al. Trends in inequalities in premature mortality: a study of 3.2 million deaths in 13 European countries. J Epidemiol Community Health. 2015;69(3):20717. https://doi.org/10.1136/jech-2014-204319.

37. Statistics Sweden (SCB). Labour market statistics, statistical database. Web page] https://www.statistikdatabasen.scb.se/pxweb/en/ssd/START_AM/. Accessed 12 May 2021.

38. Cainzos-Achirica M, Capdevila C, Vela E, Cleries M, Bilal U, Garcia-Altes A, et al. Individual income, mortality and healthcare resource use in patients with chronic heart failure living in a universal healthcare system: a population-based study in Catalonia, Spain. Int J Cardiol. 2019;277:250-7. https://doi.org/10.1016/j.ijcard.2018.10.099.

39. Schjodt I, Johnsen SP, Stromberg A, Kristensen NR, Logstrup BB. Socioeconomic factors and clinical outcomes among patients with heart failure in a universal health care system. JACC Heart Fail. 2019;7(9):746-55. https://doi.org/10.1016/j.jchf.2019.06.003.

40. Ahmad K, Chen EW, Nazir U, Cotts W, Andrade A, Trivedi AN, et al. Regional variation in the Association of Poverty and Heart Failure Mortality in the 3135 counties of the United States. J Am Heart Assoc. 2019;8(18):e012422. https://doi.org/10.1161/JAHA.119.012422.

41. Zou H, Chen Y, Fang W, Zhang Y, Fan X. The mediation effect of health literacy between subjective social status and depressive symptoms in patients with heart failure. J Psychosom Res. 2016;91:33-9. https://doi.org/1 0.1016/j.jpsychores.2016.10.006.

42. Gast A, Mathes T. Medication adherence influencing factors-an (updated) overview of systematic reviews. Syst Rev. 2019;8(1):112. https://doi.org/10.11 86/s13643-019-1014-8

43. Ahs AM, Westerling R. Mortality in relation to employment status during different levels of unemployment. Scand J Public Health. 2006;34(2):159-67. https://doi.org/10.1080/14034940510032374

44. Lofman I, Szummer K, Dahlstrom U, Jernberg T, Lund LH. Associations with and prognostic impact of chronic kidney disease in heart failure with preserved, mid-range, and reduced ejection fraction. Eur J Heart Fail. 2017; 19(12):1606-14. https://doi.org/10.1002/ejhf.821.

\section{Publisher's Note}

Springer Nature remains neutral with regard to jurisdictional claims in published maps and institutional affiliations.

Ready to submit your research? Choose BMC and benefit from:

- fast, convenient online submission

- thorough peer review by experienced researchers in your field

- rapid publication on acceptance

- support for research data, including large and complex data types

- gold Open Access which fosters wider collaboration and increased citations

- maximum visibility for your research: over $100 \mathrm{M}$ website views per year

At BMC, research is always in progress.

Learn more biomedcentral.com/submission 